\title{
Carreiras exclusivas de Estado e relações administrativas mais de Estado do que de governo
}

\author{
Juarez Freitas ${ }^{*}$
}

\section{INTRODUÇÃO}

As relações de Direito Administrativo devem ser pronunciadamente mais de Estado do que de governo. ${ }^{1}$ Assegurar a obrigatória continuidade das políticas públicas, para além do caráter episódico dos governos, figura entre as missões primordiais desse nobre ramo do sistema jurídico. No atual contexto, não há exagero em asseverar que a própria viabilidade das parcerias público-privadas, por exemplo, depende do efetivo reconhecimento da indelegabilidade de determinadas funções estatais. O Direito Administrativo afirma-se, nessa perspectiva, menos como aquele Direito da Administração executora ou prestadora direta dos serviços públicos ou universais, convertendo-se precipuamente em Direito do Estado Democrático e Regulador, num decisivo movimento transformador, mormente no presidencialismo que se caracteriza pela exacerbada concentração unipessoal das chefias de Estado e de Governo. Com efeito, a continuidade pós-

\footnotetext{
- Professor de Direito Administrativo da UFRGS, professor e coordenador do Mestrado e do Doutorado em Direito da Pontifícia Universidade Católica do Rio Grande do Sul, professor da Escola Superior da Magistratura-AJURIS, presidente do Instituto Brasileiro de Direito Administrativo, professor de Pós-Graduação em Direito no país e no exterior, pesquisador associado na Universidade de Oxford, advogado e parecerista.

1 Vide FREITAS, Juarez. O Controle dos Atos Administrativos e os Principios Fundamentais. 3. ed. São Paulo: Malheiros, 2004, revisando categorias à luz da premissa mencionada. Para cotejo, sobre as mudanças em curso, vide CASSESE, Sabino. Tendenze e Problemi del Diritto Amministrativo. Rivista Trimestrale di Diritto Pubblico, 54, p. 901912, 2004.
} 
governamental e o planejamento passam a exercer papéis maiúsculos na efetivação do complexo de princípios e regras que regem as relações de administração.

Noutros termos, mais do que nunca, indispensável a máxima (re)valorização das carreiras de Estado, robustecidas e consolidadas em regime institucional que confira estímulos e garantias compatíveis. Justamente a última asserção é que abre ensejo à reflexão sobre as carreiras de Estado, tema do presente estudo, que tem por objeto o exame do caso emblemático da Administração Tributária. ${ }^{2}$

\section{REGIME INSTITUCIONAL E CARREIRAS DE ESTADO}

Quando o constitucionalismo e o próprio Direito Administrativo ainda se achavam em fase inicial de desenvolvimento, muitos, na falta de conceitos mais apropriados, cederam à tentação de pedir auxílio às categorias do Direito Privado, ${ }^{3}$ optando pelas discutíveis virtudes do método extrapolativo, cuja lógica consiste em elucidar um ramo do Direito a partir do observado em outro mais antigo. Foi Paul Laband quem ressaltou que, nesse período embrionário, a literatura, cedendo às meras semelhanças, resolveu buscar nas figuras negociais do mandato (Harprech, Eybel, Troplong, Merlin e Laurent), da locação de serviços (Paul Kress, Wilhelm Neumann e D. Strube) - e até no contrato inominado ${ }^{4}$ (J. C. Leist e J. A. Feurbach) - a inspiração para discernir a essência da relação jurídica articulada entre o Poder Público e seus funcionários. Depois de rechaçar, uma a uma, as alternativas de cunho privatista - por definição, precárias -, Laband, procurando harmonizar a idéia de bilateralidade com os princípios do Direito Público, animouse a propor que tudo não passava de um contrato de direito público sui generis. Em seu entender, "a relação de serviço do funcionário público repousa sobre um contrato pelo qual, ..., o servidor se devota ao Estado, assume um particular dever de serviço e de fidelidade, engaja-se em um dever

2 Alinha-se o presente estudo com o Parecer que emiti, em junho de 2004, a convite honroso da Febrafite sobre aspectos da Emenda Constitucional 42/2003.

3 MIRANDA Pontes de. Comentários à Constituição de 1967 com a Emenda $n^{\circ} 1$ de 1969. São Paulo: Revista dos Tribunais, 1973, v. 3, p. 418, já notara: "como acontece quando a qualquer relação jurídica menos conhecida, procurou-se explicar a relação jurídica entre o funcionário público e o Estado, assimilando-a a algumas das relações mais vulgares no mundo do direito, em subordinação do direito público ao direito privado, característica de séculos em que o direito civil representou a preocupação principal da burguesia, após a derrocada das instituições monárquico-feudais".

4 LE DROIT Public de L'Empire Allemand. Tradução C. Gandilhon e TH. Lacuire. Paris: V. Giard, E. Brière, 1901, v. 2, p. 114-115. 
de obediência, e pelo qual o Estado, por sua vez, aceita tal promessa, assim como a singular relação de poder que the é oferecida, assegurando ao funcionário, em contrapartida, proteção e, também, sustento". 5

Graças a esse pronunciamento, Laband acabou se tornando o precursor e um dos maiores expoentes da chamada teoria contratualista que, influenciada pela atmosfera liberal reinante na segunda metade do século XIX, elegeu o princípio da autonomia como sua principal pedra de alicerce. Ocorre que as notórias inconsistências da teoria bilateral cedo vieram à tona: como compatibilizar o largo espectro das intervenções unilaterais do Poder Público, inclusive no plano dos direitos e obrigações dos servidores, com a máxima sinalagmática da mútua pactuação dos vínculos? Ainda quando se cogitasse de um "contrato sui generis", ${ }^{6}$ o certo é que, antes de se incorporar ao serviço público, o funcionário, nesse regime bilateral, teria a possibilidade de debater as condições do trabalho, as quais, uma vez acordadas, fariam lei entre os contraentes, não podendo ser modificadas pela vontade exclusiva do Estado. Ora, salta aos olhos que esse resultado nunca refletiu a realidade que, já então, marcava as relações entre o Poder Público e seu corpo de funcionários.

O passo seguinte, nesse renhido debate, coube à criatividade de Otto Mayer. Insurgindo-se, de um lado, contra a tese contratualista de seu colega Laband e, de outro, contra a anacrônica influência privatista da época, alertou para a circunstância de que o vínculo entre Estado e servidor público não tinha, propriamente, origem em um contrato de trabalho (público ou privado). Repousava, antes, numa "obrigação de servir de direito público"? Rejeitando, assim, as antigas concepções da gestão de negócios, da locação de serviços e do mandato, Mayer adverte que "a função é um círculo de atividades do Estado que devem ser geridas por uma pessoa

5 Ibidem, p. 119-120: "Le rapport de service du fonctionnaire de l'Etat repose sur un contrat par lequel, ..., contracte un devoir particulier de service et de fidélité, s'angage à un dévouement particulier, à une obéissance particulièr, et par lequel l'Etat accepte cette promesse, ainsi que le rapport de puissence particulier qui lui est offert et assure en retour au fonctionnaire protection et, d'ordinaire, entretien".

6 Entre nós, M. I. Carvalho de Mendonça e Clóvis Beviláqua se incluem no rol dos juristas que acolheram a concep̧̧ão do "contrato sui generis". Sobre o tema, vide MIRANDA, Comentários..., p. 428.

7 MAYER, Otto. Droit Aministratif Allemand. Paris: V. Giard; E. Brière, 1906, v. 4, §42, p. 8: "La fonction publique, au contraire, est essentiellement liée à obligation de servir du droit public". 
ligada por uma obrigação de direito público de servir ao Estado".

Mas o passo crucial no sentido de superar, ao se cogitar de servidores tipicamente estatais, a noção de contrato foi dado por uma tríade de renomados juristas franceses: Léon Duguit, Maurice Hauriou e Gaston Jèze. Ao dissociarem a realidade jurídica dos servidores públicos daquela de outras espécies de empregados da Administração, cujas relações de trabalho eram disciplinadas por regras do direito privado, em uníssono, trataram de repudiar o processo de colonização do Direito Público pela doutrina privatista, demarcando, ato contínuo, as características assaz peculiares do estatuto publicista reservado aos "funcionários propriamente ditos" (fonctionnaire proprement dit).

Duguit, aludindo à "situação geral dos funcionários", escreveu que a palavra estatuto designa a situação especial constituída para os funcionários pela aplicação das disposições legais ou regulamentares editadas para protegê-los contra todos os atos arbitrários dos governantes ou de seus agentes diretos. Esta definição do estatuto basta para mostrar que ele constitui, essencialmente, uma situação de direito objetivo resultante, diretamente, da aplicação do direito objetivo formulado pelas leis e pelos regulamentos do serviço público considerado. ${ }^{10}$

É o que, com idêntico sentido e com linguagem assemelhada, enunciou Hauriou, ressaltando que se a

8 Ibidem, p. 8: "La fonction est un cercle d'affaires de l'Etat, qui doivent être gérées par une personne liée par l'obligation de droit public de servir l'Etat". Sobre o confronto entre Laband e Otto Mayer vide, por exemplo, FLEINER, Fritz. Droit Administratif Allemand. Tradução Dh. Eisenmann. Paris: Librairie Dalegrave, 1933, que, por sua vez, seguiu o pensamento de Otto Mayer, sustentando que a opinião de Laband "ne peut cepandant pas être acceptée. La nomination du fonctionnaire comme la naturalisation de l'étranger sont l'oeuvre d'une disposition unilatérale de l'autorité, mais d'une disposition que l'autorité ne peut édicter qu'avec l'assentiment de l'intéressé" (p. 123). Na década de 50, Friedrich Giese in Allgemeines Verwaltungsrecht. Tübingen: J.C.B. Mohr (Paul Siebeck), 1952, p. 55, também acolheu a ótica de que "die Ernennung ist kein öffentilich-rechtlicher Vertrag, sondern ein einseitiger Staatshoheitsakt". Atuamente, a visão que prevalece é a de que se trata de ato administrativo, como mostra MAURER, Hartmut. Allgemeines Verwaltungsrecht. München: C.H. Beck'sche, 1985, p. 146.

9 DUGUIT, Leon. Traité de Droit Constitutionnel. Paris: Ancienne Librairie Fontemoing, 1930 , v. 3, p. 159: "[...] situation générale des fonctionnaires...".

10 Ibidem, p. 159: "Le mot statut désigne la situation spéciale qui est faite aux fonctionnaires par l'application des dispositions légales ou réglementaires édictées pour les protéger contre tous actes arbitraires de la part des gouvernants et de leurs agents directs. Cette définition du statut suffit à montrer qu'il constitue essentiellement une situation de droit objectif résultant directement de l'application du droit objectif formulée par les lois e règlements du service public considéré". 
concepção do contrato de serviço público deve ser afastada para os funcionários propriamente ditos e se, inclusive, se deve evitar dizer que, no todo de sua relação, o funcionário se liga à Administração como uma parte à outra parte, pela boa razão de que funcionário e Administração são um dentro da instituição administrativa, não resta outra solução jurídica possível senão a de que o funcionário seja incorporado à Administração por uma requisição consentida que lhe confere um estatuto legal regulamentar e moral. ${ }^{11}$

Gaston Jèze, com seu inconfundível estilo oratório, também reproduziu esse prisma, consoante o qual, "na França, os agentes do serviço público propriamente ditos estão em uma situação jurídica legal e regulamentar. Isso significa que o sistema do contrato não intervém em nenhum momento. Não é um contrato que incorpora o agente ao serviço público. Não é um contrato que regula os direitos e obrigações dos indivíduos no serviço público. Não é um contrato que fixa a duração das funções e as condições de exoneração do serviço público. A sanção dos direitos e das obrigações dos agentes do serviço público não é aquela dos direitos e obrigações resultantes de um contrato". ${ }^{22}$

11 HARIOU, Maurice. Précis Élémentaire de Droit Administratif. Paris: Recueil Sirey, 1938, p. 72: "Si la conception du contrat de service public doit être écartée pour le fonctionnaire proprement dit et si même on doit éviter de dire que, pour l'ensemble de sa situation, le fonctionnaire soit lie à l'administration comme une partie à une autre partie, pour la bonne raison que fonctionnaire et administration ne font qu'un dans l'institution administrative, il reste qu'une solution juridique possible, à savoir que le fonctionnaire soit rattaché à l'administration par une réquisition consentie lui conférant un statut légal réglementaire et moral".

12 JÈZE, Gaston. Les Principes Généraux du Droit Administratif. Paris: Marcel Giard, 1930, p. 244 e 145: "En France, les agents au service public proprement dits sont dans une situation juridique légale et réglementaire. Cela signifie que le procédé du contrat n'intervient à aucun moment. Ce n'est pas un contrat qui fait entrer les agents au service public. Ce n'est pas un contrat qui règle les droits et obligations des individus au service public. Ce n'est pas un contrat qui fixe la durée des functions et les conditions de la sortie du service public. La sanction des droit et obligations des agents au service public n'est pas celle des droits et obligations résultant d'un contrat". André de Laubadère, em 1968 (num trabalho que foi publicado nos Annales de la Faculté de Droit et des Sciences Économiques de Toulouse - faculdade em que lecionara Maurice Hauriou -e, também, no volume I, das Pages de Doctrine. Paris: LGDJ, 1980) lembrou, com lucidez, que, apesar das abertas divergências, sobretudo quanto ao modo de pensar a ciência jurídica, "c'est également un accord des deux grands maîtres [Duguit e Hauriou] que l'on rencontre, dans la théorie de la fonction public, sur des points fondamentaux, considérés depuis lors comme acquis: le rejet de la notion de contrat pour définir le lien unissant des fonctionnaire à l'intérieur de l'administration [...]" (HARIOU, Maurice. Pages de Doctrine. Paris: LGDJ, 1980, v. 1, p. 27). 
Como não poderia deixar de ser, o eco das concepções francesa e alemã repercutiu entre nós. No Brasil, foi Pontes de Miranda um dos que mais aprofundadamente meditaram sobre a matéria. Embora o sistema constitucional brasileiro - de $1946^{13}$ para cá tenha sofrido abrangentes mutações na seara do regime jurídico dos servidores públicos, não se pode negar que, no plano das linhas mestras, a reflexão ponteana sobre o trabalho público ostenta o raro mérito de resistir a sobressaltos e às mudanças circunstanciais, transformando-se, em questões nevrálgicas, numa fonte preciosa, não só de orientação segura para os administradores, mas, igualmente, de esclarecido alerta para os legisladores.

Depois de investigar as diferentes teorias que disputavam a preferência da comunidade jurídica, detendo-se na polêmica que acirrara os ânimos entre os adeptos do regime contratual (bilateralidade) e da corrente estatutária (unilateralidade), Pontes pondera, com sagacidade, que para discernir qual o enfoque mais correto, convém, antes de mais nada, ter presente que, enquanto "a relação jurídica é sempre bilateral, porque exige, pelo menos, dois pólos", apenas "a fonte da relação jurídica é que pode ser unilateral, ou bilateral, ou plurilateral". ${ }^{4}$ Quer dizer: embora toda relação jurídica seja bilateral, nem todas as relações jurídicas vêm ao mundo ungidas pela bilateralidade. É preciso não confundir a necessária bilateralidade dos efeitos com a eventual bilateralidade das fontes. Não se deve negligenciar a evidência de que a polaridade na relação é um a posteriori cujo a priori, não raro, é a unilateralidade. Segundo Pontes, esse parece ser, sem rasuras, o caso da relação entre Estado e servidor público. Trata-se, de modo nítido, de posição jurídica da qual emergem incontáveis efeitos bilaterais. Todavia, não há como despistar o dado concreto de que, lá no princípio, no bojo originário de suas fontes, "a vontade dos figurantes como que desaparece: não só a vontade do funcionário público, ou do candidato à investidura, nos cargos públicos, mas, também, a do próprio Estado [...]". ${ }^{15}$ É por isso que Pontes, armado de bons argumentos, afirma que "o elemento institucional é predominante, quase exclusivo", motivo pelo qual "trata-se de relação jurídica (portanto, bilateral), mas institucional, o que repele a noção de pura contratualidade". ${ }^{16}$

13 A escolha da Constituição de 46 como marco se explica pelo fato de que foi ao comentála que Pontes parece haver amadurecido o seu posicionamento sobre o tema dos funcionários públicos. Não se olvida, portanto, que Pontes, antes da Constituição de 46, já comentara a de 34 .

14 MIRANDA, Comentários..., p. 432.

15 Ibidem, p. 431.

16 MIRANDA, Comentários..., p. 431. 
Como se nota, a conclusão de Pontes, a despeito de divergências laterais, não desmente, no geral, o entendimento, quase em tudo convergente, de Mayer, Duguit, Hauriou e Jèze, vale dizer: à diferença do chamado empregado público, cujo contrato de trabalho é regido basicamente pela CLT, ${ }^{17}$ a situação jurídica do servidor público "propriamente dito" é, sim, estatutária ou legal.

Com efeito, a disciplina em vigor não tornou obsoletas, no particular, nenhuma das observações doutrinárias mencionadas. Ninguém ignora que a modificação do art. 39 da $\mathrm{CF} / 88$, promovida pela Emenda 19/98, tentou, de modo formalmente inconstitucional, descontinuar o "regime jurídico único", ampliando, em contrapartida, o âmbito de utilização da figura do empregado público, cujas relações com o Estado são disciplinadas, basicamente, pelas regras constantes da Consolidação das Leis do Trabalho - CLT. Afigura-se irretorquível, entretanto, que subsiste, incólume, o regime institucional. Não deixam margem para maior dúvida as

17 O dualismo entre servidores públicos estatutários (vínculo institucional de Direito Público) e empregados públicos (contrato de trabalho) conserva-se na Alemanha, na França e, também, no nosso sistema. Entre os alemães, HESSE, Konrad. Grundzüge des Verfassugsrechts der Bundesrepublik Deutschland. Heidelberg: C. F. Müller Juristischer, 1978, p. 218 eACHTERBERG, Norbert. Allgemeines Verwaltungsrecht. Heidelberg: Decker, C. F. Müller, 1982, p. 194) confirmam esse dualismo entre "Beamter" (servidor público estatutário) e "Angestelte" (empregado público), que vem de longe (Constituição de Weimar). Entre os franceses, Yves Gaudemet, ao atualizar o Tratado de André de Laubadère, esclarece que "a la différence du personnel fonctionnaire, uniformément soumis à une situation légale ou réglementaire de droit public, le personnel non fonctionnaire relève de régimes juridiques divers" (Traité de Droit Administratif. Paris: L.G.D.J., 1998, p. 40). Entre nós, a doutrina é uniforme no sentido de reconhecer que "a Constituição admite, na própria Administração direta, nas autarquias e fundações públicas, que certas atividades possam ser desenvolvidas sob regime de emprego" (BANDEIRA DE MELLO, Celso Antônio. Curso de Direito Administrativo. São Paulo: Malheiros, 2003, p. 240). Isso quer significar que, "embora o regime de cargo tenha que ser o normal, o dominante, na Administração direta, autárquica e fundações de Direito público, há casos em que o regime trabalhista (nunca puro, mas afetado, tal como se averbou inicialmente, pela interferência de determinados preceitos de Direito Público) é admissível para o desempenho de algumas atividades; aquelas cujo desempenho sob regime laboral não compromete os objetivos que impõem a adoção do regime estatutário como normal, o dominante" (Ibidem, p. 242). São do mesmo entendimento, por exemplo, MEIRELLES, Hely Lopes. Direito Administrativo Brasileiro. São Paulo: Malheiros, 2001, p. 383; MEDAUAR, Odete. Direito Administrativo Moderno. São Paulo: Revista dos Tribunais, 2002, p. 333; DI PIETRO, Maria Sylvia Zanella Direito Administrativo. São Paulo: Atlas, 2001, p. 424 e MOREIRA NETO, Diogo de Figueiredo. Curso de Direito Administrativo. Rio de Janeiro: Forense, 2003, p. 276. 
inúmeras alusões, no texto da Lei Fundamental, à categoria dos servidores titulares de cargos públicos na Administração direta, nas autarquias, nas fundações de Direito Público e na esfera administrativa do Poder Legislativo e do Poder Judiciário.

Do regime estatutário ou institucional decorre bom número de conseqüências dignas de registro. É auspicioso que o constituinte derivado, apesar das vastas reformas que vem promovendo na esfera dos direitos dos servidores públicos - não raro, desafiadoras, para dizer o mínimo, da resiliência constitucional -, felizmente não abandonou o reconhecimento de que, para a segurança da sociedade e para a eficiência do serviço público, convém reservar aos ocupantes de certos cargos efetivos um tratamento especial, apto a propiciar a formação de uma carreira com o irrenunciável e profissional atributo da competência e capaz de colocar seus membros a salvo das cooptações partidárias, ${ }^{18}$ da descontinuidade governativa, assim como das ásperas angústias relacionadas à subsistência incerta na velhice.

Alexander Hamilton, faz tempo, observou: só o que detém controle sobre o próprio sustento mantém altivo domínio sobre a vontade. ${ }^{19}$ Pessoas cuja sobrevivência depende da maré oscilante e fortuita da sorte ou da ascendência calculista de terceiros transformam-se, às vezes, em servos indefesos, no mercado opressivo dos interesses econômicos e políticos. Dessa maneira, ontem como agora, perdura intacta, no fundamental, a idéia de "que o melhor meio de assegurar um bom funcionamento dos serviços públicos é conferir aos funcionários, legalmente, uma situação estável". ${ }^{20}$

O trágico inventário das tentativas de supressão radical do regime estatutário e de suas respectivas garantias institucionais, sobretudo a da estabilidade, atesta que jamais foram bem-sucedidas. Um caso notável foi o de Andrew Jackson nos EUA. Apesar daquele célebre alerta de Hamilton no final do século XVIII, chamando

18 Como lembra FLEINER, Droit administratif..., p. 66-67, naAlemanha, ja "la Constitution d'Empeire a cherché à parer au danger d'une introduction de la politique dans l'administration (Politisierung der Verwaltung) et de l'exercice d'influences de parti sur les fonctionnaires en proclamant le principe - qui va de soi - que 'les fonctionnaires sont les serviteurs de la collectivité, non d'un parti' ( art. 130, al. 1)".

19 Como sublinha HAMILTON, Alexander. The Federalist. Chicago: Encyclopaedia Britannica, 1952, v. $43, n^{\circ} 79$, p. 233 , "In the general course of human nature, a power over a man's subsistence amounts to a power over his will".

20 DUGUIT, Traité du droit..., v.3, p. 149-150: “Alors est née cette idée éminemment juste que le meilleur moyen d'assurer un bon fonctionnement des services publics, c'est de conférer légalement aux fonctionnaire une situation stable". 
atenção para que se cuidasse de resguardar a independência dos servidores, o Presidente Jackson, em 1829, desnaturando o sistema da due participation criado por Thomas Jefferson, houve por bem introduzir a doutrina do spoils system. Tal sistema conseguiu ser pior do que a mais equivocada aplicação da fórmula da "devida participação" que, concebida por Jefferson em bases de estrita igualdade entre os partidos, logo se converteu em reflexo proporcional ao desempenho nas eleições. $O$ mecanismo da "devida participação" estava longe de ser o ideal, contudo o substitutivo posto em voga por Jackson sobrepujou-o, em muito, nas mazelas. Em contraste com o sistema da "devida participação", a alternativa prescrita por Jackson "degenerou em mero partidarismo". ${ }^{21}$

O critério adotado por Jackson, sem apreço pela idéia de profissionalismo, foi, em resumo, o da simples rotatividade nos cargos. Como bem percebeu Gaston Jèze, "Jackson preconizava a seguinte regra: a cada um a sua vez". ${ }^{22}$ Vale a pena transcrever o juízo que o eminente jurista francês formou a respeito dessa proposta indefensável: "O certo é que os resultados do sistema dos despojos foram deploráveis. Em poucos anos, os hábitos de concussão, imoralidade, introduziram-se na administração americana. Os abusos foram tais que levaram, em 1883, a uma reação que operou uma mudança radical no recrutamento da função pública (sistema do concurso)". ${ }^{23}$

Atualmente, no Brasil dos escândalos, convém não perder de vista tal advertência histórica. As emendas constitucionais $n^{\circ} \mathrm{s} 19,20$ e 41 promoveram sucessivas e substanciais alterações (intertemporalmente geradoras de tumulto), criando perigosos mecanismos de relativização da estabilidade e até reformando o que já havia sido reformado: novas regras aplicáveis às aposentadorias do setor público. Do ponto de vista publicista, as mudanças, no geral, não foram de boa filosofia. Mal compostas, algumas das modificações merecem severas críticas, tanto jurídicas como políticas. Nada obstante, seria unilateralismo

21 WHITE, Leonard. Introduction to the Study of Public Administration. New York: The Macmillan, 1957, p. 18: "Contrary to Jackson's expectation, rotation degenerated into mere partisanship"

22 JÈZE, Les Principes..., p. 405: "En termes plus nets, Jackson préconisait la règles: chacun son tour!".

23 Ibidem, p. 405: “Ce qui est certain, c'est que les résultats du système des dépouilles furent déplorables. En quelques années, les habitudes de concussion, l'immoralité, s'introduisirent dans l'administration américane. Le abus furent tels qu'ils amenèrent en 1883 une réaction et firent opérer un changement radical dans le recrutement de la fonction public (système du concours)". 
negar que o constituinte teve alguns acertos. Assim, consciente de que o futuro das instituições depende, em larga medida, da salvaguarda de algumas carreiras de Estado, sem as quais periclitam a continuidade e o funcionamento da Administração Pública (da União, dos Estados, do Distrito Federal e dos Municípios), o Congresso Nacional deixou, aqui e acolá, sinais de cautela e prudência.

É precisamente nesse rol em que se encaixam o acréscimo do inciso XXII ao art. 37 e a nova redação conferida ao inciso IV do art. 167, todos da Constituição Federal (EC 42/2003). Deveras, o sentido finalístico e sistemático de ambos os dispositivos é confluente com a perspectiva de estatuir tratamento diferenciado para determinadas carreiras de cuja atuação eficiente, proba e estável depende o funcionamento não só de todas as instituições públicas, mas, também, e sobretudo, da sociedade civil: o mundo contemporâneo assemelha-se a um complexo sistema vivo e não é preciso grande argumentação para se convencer que determinados órgãos são mais vitais do que outros.

A propósito, o estudo da situação jurídica da "Administração Tributária" constitui boa e emblemática ilustração da necessidade de fortalecimento institucional. De fato, quando se lança o olhar investigativo em direção ao passado, observa-se que certas idéias constituem a culminância de processo evolutivo que remonta a longes tempos. Não se trata, aqui, do apego supersticioso a velhos hábitos. Não. É apenas o reconhecimento de que, sob vários aspectos, não se faz viável compreender o presente sem consultar a provada sabedoria dos que nos antecederam. Ora, a decisão de conferir às "Administrações Tributárias da União, dos Estados, do Distrito Federal e dos Municípios" a elevada dignidade de "atividades essenciais ao funcionamento do Estado" e, nessa medida, de permitir, excepcionalmente, "a vinculação de receita de impostos... para realização de atividades de administração tributária", só experimenta nitidez se projetada sob o pano de fundo histórico que, de forma quase ininterrupta, conservou-se fiel à idéia de que os organi essenziali $e$ principali dell'attività tributaria ${ }^{24}$ reclamam, para a defesa e para o guarnecimento da sociedade, uma disciplina normativa especial.

Não é de hoje, com efeito, que as atividades que gravitam em torno da gestão e da fiscalização tributárias gozam de status jurídico eminente. Assim a Roma da República, assim a do Principado, aquela com o aerarium e os quaestores, esta com as novidades do fiscus e dos praefecti aerarii (sem falar nos procuratores fisci, no

24 GANGEMI, Lello. Elementi di Amministrazione Finanziaria Pubblica. Padova: CEDAM, 1934, p. 109 et seq. 
praetor fiscalis e nos advocati fisci), conheceram a preocupação, essencial para o resguardo do vigor romani, de manter aparato burocrático e administrativo eficiente e estável, ao mesmo tempo.

Para se ter precisa idéia da relevância das funções desempenhadas, no início do período da República, pelos quaestores, basta lembrar que o cônsul - a mais alta magistratura de então - era obrigado a se fazer assistir pelo questor toda vez que retirasse dinheiro do tesouro, provavelmente seguindo um procedimento no qual o questor remetia os recursos financeiros solicitados pelo cônsul e registrava em seus livros a soma desembolsada. ${ }^{25}$ Isso significa que, eleito "pelo mérito", ${ }^{26}$ "o questor exerce, nesse primeiro caso, uma representação indispensável...", ${ }^{27}$ de cuja mediação até o cônsul depende.
Como uma magistratura patrícia, ordinária e cum potestas - isto é, com a "faculdade de exprimir, com a própria vontade, a vontade do Estado, criando direitos e obrigações" 28 -, os questores ocupavam o ápice da estrutura administrativa romana, ficando abaixo somente das magistraturas cum império. ${ }^{29}$

No Principado, a partir de Augusto, surge, ademais, o praefectus aerarii. Àquela altura, entre os funcionários romanos, a categoria do praefectum (prefeito) é de todas a mais relevante. ${ }^{30}$ O significado da palavra praefectum, que designa o "representante de uma autoridade superior", já denuncia a situação de destaque dos praefecti aerarii, que, escolhidos diretamente pelo princeps, representam-no na gestão do aerarium, bem como na do fiscus, podendo, o que o distingue de semelhantes magistraturas, receber

25 MOMMSEN, Théodor. Manuel des Antiquités Romaines. Tradução Paul Frédéric Girard. Paris: Thorin et Fils, 1894, v. 4, p. 244: "[...] le consul était obligé de se faire assister du questeur toutes les fois qu'il retirait de l'argent du trésor, probablement sous cette forme que le questeur remettait l'aegent au consul sur l'ordre de celui-ci et inscrivait sur ses livres la somme déboursée".

26 TACITO. The Annals. Tradução Alfred John Church e William Jackson Brofribb. Chigago: Great Books, [s.d.], v. 15, p. 106: " [...] the quaestorship was obtained, ..., by merit in the candidates ...".

27 MOMMSEN, op. cit., p. 244: "Par conséquent, le questeur qui exerçait dans le premier cas une représentation indispensable ...".

28 ARANGIO-RUIZ, Vincenzo. Storia del Diritto Romano. Napoli: Eugenio Jovene, 1968, p. 31: "[...] la facoltà di esprimere con la propria volontà quella dello Stato, creandogli diritti ed oblighi; [...]".

29 Vide MOREIRAALVES, José Carlos. Direito Romano. Rio de Janeiro: Forense, 1971, v. 1, p. 30 .

30 Ibidem, p. 50. 
"recompensas especiais ... em caso de boa administração". ${ }^{31} \mathrm{~A}$ independência desses funcionários responsáveis pela condução dos negócios públicos pode ser aquilatada pelo fato de que, "mesmo durante a mais turbulenta luta pelo poder... o aparato administrativo continuou a desenvolver com notável regularidade as suas funções, [...]. E se isso vale para a administração em geral, vale, ainda mais, para a administração financeira". ${ }^{32}$

A melhor parcela da herança portuguesa não destoa dessa antiga orientação de atribuir altos galardões aos funcionários encarregados de gerir as contas públicas. Em Portugal, na hierarquia da Administração do Rei D. Afonso $\mathrm{V}$, logo abaixo do Alferes-mor - o cargo mais elevado -, encontravase, então, Senex ou Calculus, ${ }^{33}$ servidor responsável pelo controle das receitas e das despesas da Casa Real. Segundo o texto das Ordenações Afonsinas, tal condição se justificava pelo fato de que "todos os haveres passavam pelas suas mãos, e isso é coisa que move muito o coração dos homens". ${ }^{34}$

Seis séculos depois dessa lúcida advertência constante das Ordenações Afonsinas, Andrew Jackson, desafiando a tradição americana que remontava a Alexander Hamilton, deliberou fazer ouvidos moucos às lições da

31 MOMMSEN, Manuel..., p. 260-161: "La perspective de récompenses spéciales leur était ouverte au cas de bonne administration".

32 ORESTANO, Ricardo. Il Problema delle Persone Giuridiche in Diritto Romano. Torino: G. Giappichelli, 1968, p. 255: "[...] anche durante le più turbinose lotte per il potere ..., l'apparato amministrativo há continuato a svolgere con notevole regolarità le sue funzione, .... E se questo vale per l'amministrazione in generale, vale ancor più per l'amministrazione finanziaria". Como ressalta Orestano, "no exercício de sua atividade o aparato fiscal opera, de fato, como organização em larga medida independente da pessoa imperador, por meio de uma vastíssima burocracia cujos membros são escolhidos entre os adictos da casa imperial [...], aos quais é reconhecido um poder de iniciativa assaz extenso, confirmado por vários princípios" ("Nell'espletamento delle sua attività l'apparato fiscale opera infatti come organizzazione in larga misura indipendente dalla persona del princeps attraverso una vastissima burocrazia i cui membri sono scelti tra gli addetti alla cassa imperiale [...], alla quale è riconosciuto un podere d'iniziativa abbastanza esteso, confermato da vari principi" (Ibidem, p. 255).

33 De acordo com as Ordenações Afonsinas, Livro I, Título LVII, o mordomo-mor também era chamado de Senex, que em latim quereria dizer velho, pelo fato de que desempenhava ofício honrado. Já o designativo Calculus, ainda com base nas Ordenações Afonsinas, evocava a pedra com que os antigos faziam suas contas.

34 PORTUGAL. Ordenações Afonsinas. Lisboa: Calouste, 1984, v. 1, Livro 1, Título LVII, p. 337: “..., porque todo o haver paffa per fua maaõ, que he coufa, que move muito os coraçoões dos homees". Sobre a condição de superioridade do Mordomo-mor, vide, ainda, MIRANDA, Comentários..., p. 440-441. 
história e duvidar da vulnerabilidade daqueles que zelavam pelo destino das receitas públicas. O desfecho, como enfatizado, sobretudo no que concerne à Administração Tributária, foi um constrangedor desastre. O desprestígio inoculado pelas reformas de Jackson no âmbito do serviço público, além de responsável pelo rápido declínio da eficiência administrativa, acabou por ensejar episódios estrepitosos. "Desses - conta Leonard White - o mais notável foi o caso do [...] coletor de impostos nomeado por Jackson para o Porto de New York, o qual fugiu para Espanha, em 1837, com algo em torno de $\$ 1.250 .000 ",{ }^{35}$ uma cifra, sem dúvida, nababesca para os padrões da época.

Foram precedentes do gênero que estimularam a doutrina, em décadas mais recentes, a recomendar, como forma de prevenir fraudes e corrupção na área das contas públicas, que o pessoal ligado ao controle e à fiscalização esteja protegido por uma relação especial, estável e bem remunerada. Adolf Wagner, um dos clássicos da Ciência das Finanças, sublinhava, a propósito, que bons resultados nesse campo só seriam obtidos "organizando logicamente o serviço e concedendo uma situação conveniente aos servidores", ${ }^{36}$ os quais deveriam ser "bem pagos e bem treinados". ${ }^{37}$

Em termos de "organização lógica do serviço" e de garantia de "uma situação conveniente aos servidores", um dos princípios universalmente adotados foi o de que as atividades de fiscalização tributária (no exercício de indelegável poder de polícia fiscal) deveriam ser, sempre e sempre, desempenhadas por pessoas jurídicas de direito público, valendo-se, nessa medida, da performance profissional e segura de servidores ocupantes de cargos efetivos, vale dizer, cargos que, em nosso ordenamento, gozam das garantias peculiares do regime institucional. ${ }^{38}$ Em grau diferenciado, o trabalho da Administração Tributária costuma ser fustigado pela influência de dois fortes grupos de pressão: de um lado, "os partidos políticos" que a "cercam por todos os lados" e, de outro, "fora da política", mas por ela secundada, a sedutora persuasão dos fiscalizados, "cujos interesses são, por vezes, atingidos pelas deliberações administrativas". ${ }^{39}$ Assim, numa ordem

35 In op. cit., p. 309: "Of these perhaps the most remarkable was the case [...] collector of the port of New York, who fled to Spain in 1837 with something over $\$ 1.250 .000$ ".

36 WAGNER, Adolf. Traité de la Science des Finances. Tradução Jules Ronjat. Paris: V. Giard, E. Brière, 1909, p. 482: “ [...] en organisant logiquement le serviçe et en donnant une situation convenable aux employés, [...]".

37 Ibidem, p. 468: "[...] bien payés et bien instruits".

38 Sobre garantias institucionais, em sentido largo, há lições preciosas do mestre BONAVIDES, Paulo. Curso de Direito Constitucional. São Paulo: Malheiros, 1996, p.492. 39 MIRANDA, Comentários..., p. 418. 
constitucional em que a Administração Tributária tem por munus garantir a máxima eficácia da rede de tributos, conferindo de perto a regular incidência, admitir-se que as suas funções possam ser exercidas por entidades de direito privado ou por empregados nãoestatutários (ainda que concursados), ou por meros ocupantes de cargo de confiança, representa quebrar o sistema pela base.

A par disso, depois de lastimar que a moralidade média ainda não estivesse elevada o suficiente para erradicar os efeitos perversos da malícia, Albert Hensel mostrou que a Administração Tributária, como "representante da autoridade do Estado", 40 serve para impedir que "nenhuma pretensão de imposto, por menor que seja, se subtraia, em qualquer caso, ao pagamento". ${ }^{41}$ Com acerto, o Professor da Universidade de Königsberg destaca que, no moderno Estado de Direito, "também a administração tributária (ou sobretudo ela!) serve, enfim, à realização do ordenamento jurídico objetivo", ${ }^{42}$ motivo pelo qual, "livre de qualquer influência" ${ }^{43}$ deve estar, efetiva e materialmente, em condições de se sobrepor, quer ao arbítrio da política, quer ao estigma da condescendência. A verdade é que um aparelho estatal incapaz de se proteger das investidas dos agentes políticos transitórios ou das perversões do mercado acaba oscilando, como pêndulo, entre os extremos deletérios da interpretação pro fisco ou da interpretação contra fiscum. Ocorre que uma e outra não se amoldam aos desígnios imparciais e superiores do Estado de Direito. ${ }^{44} \mathrm{Nem}$ pro fisco, tampouco contra fiscum. Antes, a atuação da "Administração Tributária do Estado" (amministrazione tributaria dello Stato) há de ser, de forma isenta, pro lege, constitucionalmente justificável no primado dos direitos fundamentais.

Pois bem, semelhante mescla de rigor e de eqüidade na ação apenas se oferece em contexto jurídico singular. Foi o que percebeu, há muito, a melhor doutrina ao discutir a possibilidade do exercício do "poder de polícia" por pessoas jurídicas de direito privado.

40 HENSEL, Albert. Diritto Tributario. Tradução Dino Jarach. Milano: Giuffrè, 1956, p. 165: "[...] rappresentante dell'autorità dello Stato [...]".

41 Ibidem, p. 163: “... che nessuna pretesa d'imposto, anche solo possibile, si sottragga in nessun caso al soddisfacimento".

42 Ibidem, p. 165: "Anche l'attività amministrativa tributaria (o piuttosto proprio questa!) serve infine alla realizzazione dell'ordinamento giuridico obbiettivo".

43 Ibidem, p. 169: “... sottrata ad ongi ... influenza, ...”.

44 Sobre o excesso de exação da Administração Tributária, vide, por exemplo, MACHADO, Hugo de Brito. Estudos de Direito Penal Tributário. São Paulo: Atlas, 2002, p. 188 et seq. 
Contra tal hipótese se pronunciou o entendimento majoritário da comunidade científica, impugnando-a com argumentos, já de ordem moral e administrativa, já de caráter jurídico e constitucional. ${ }^{45}$ Mas isso foi também o que os legisladores enxergaram e, sem demora, consagraram, de maneira expressa, no texto do Código Tributário Nacional, declarando, no seu art. $7^{\circ}, \S$ $3^{\circ}$, que: A competência tributária é indelegável, salvo atribuição das funções de arrecadar ou fiscalizar tributos, ou de executar leis, serviços, atos ou decisões administrativas em matéria tributária, conferida por uma pessoa jurídica de direito público a outra. “[...] $\S 3^{\circ}$ Não constitui delegação de competência o cometimento, a pessoas de direito privado, do encargo ou da função de arrecadar tributos. Como se constata, somente pessoa jurídica de direito público pode desempenhar atividades próprias da fiscalização tributária.

Aliomar Baleeiro, desde o início, observara, ao comentar o Código Tributário Nacional, que "a delegação para... fiscalização é restrita às pessoas de Direito Público" ${ }^{46}$ o que importa dizer que a delegação à pessoa jurídica de direito privado encontra-se vedada. ${ }^{47}$ O máximo que pode haver é transferência à pessoa de direito privado da mera função instrumental de arrecadar, ${ }^{48}$ como, aliás, em visível simetria com o Direito

45 Vide FREITAS, Juarez. Estudos de Direito Administrativo. São Paulo: Malheiros, 1995, p. 54: "Outra característica nodal é a de que a polícia administrativa há de ser exercício privativo do Poder Público, [...]". É o que também ensinava Ruy Cirne Lima, quando escreveu que "traço característico da limitação ou restrição policial é o de ser imposta pelo poder público privativamente" (LIMA, Ruy. Princípios de Direito Administrativo. São Paulo: Revista dos Tribunais, 1982, p. 107).

46 BALEEIRO, Aliomar. Direito Tributário Brasileiro. Rio de Janeiro: Forense, 2004, p. 80.

47 A propósito, vide MACHADO, Hugo de Brito. Comentários ao Código Tributário Nacional. São Paulo: Atlas, 2003, v. 1, p. 156: "A reposta afirmativa à última daquelas questões pode ser sustentada, especialmente tendo-se em vista que a atribuição das funções em tela [atividade de fiscalização] não pode ser feita a pessoa jurídica de Direito Privado". Vide, ainda, MACHADO, Hugo de Brito. Curso de Direito Tributário. São Paulo: Malheiros, 2004, p. 256. Com igual ponto de vista, vide, ademais, MORAES, Bernardo Ribeiro de. Compêndio de Direito Tributário. Rio de Janeiro: Forense, 1993, v. 1, p. 269. 48 A tal respeito, MACHADO, Curso de..., p. 256, assim se posiciona: "Não constitui delegação de competência tributária o cometimento a pessoas de direito privado do encargo ou da função de arrecadar tributos (CTN, art. $\left.7^{\circ}, \S 3^{\circ}\right)$. Simples função de caixa, que hoje é atribuída aos estabelecimentos bancários". 
Romano, ${ }^{49}$ tem acontecido, atualmente, com vários estabelecimentos bancários, cuja rede de agências, mais próxima do contribuinte, permite eficiência, agilidade e conforto no recolhimento dos tributos em geral.

Mas o caráter diferenciado das regras disciplinadoras do exercício do "poder de polícia" - e a fiscalização tributária configura somente uma das espécies-, também implicou a peculiar condição jurídica dos servidores incumbidos de representar o Estado no manejo dos instrumentos de intervenção reguladora na esfera dos interesses particulares. Nesse sentido, o entendimento majoritário nunca deixou de proclamar que o desempenho profícuo do "poder de polícia" reclama, em face das injunções políticas e das sedições do mundo do mercado, uma blindagem em torno do servidor, que só as garantias do cargo de carreira estatutária podem erigir.

49 Aqui reaparece o fio contínuo da história. Apesar dos inegáveis contrastes entre os contextos institucionais, as semelhanças com o Direito Romano outra vez vêm a lume. Enquanto a função fiscalizatória propriamente dita ficava nas mãos de um Magistrado (do quaestor na República e dos praefecti aerarii no Principado), a função arrecadatória era desempenhada pelos publicani, que operavam no seio de uma societas publicanorum por eles constituída (v. KASER Max. Das Römische Privatrecht. München: C.H. Beck'sche Verlagsbuchhandlung, 1955, p. 263 et seq.; e KUNKEL, Wolfgang. Römische Rechtsgeschichte. Köln: Böhlau, 1956, p. 26). No primeiro caso, tratava-se de típica relação de direito público, em que a "posizione 'pubblicistica" (v. ORESTANO, Il Problema..., p. 256) que vincula o quaestor ao aerarium e os praefecti aerarii ao princeps saltava aos olhos. No segundo caso, ao contrário, já se localiza também a presença do direito privado, com a intervenção de particulares, os publicani e as societates publicanorum, em vínculo de colaboração com o Poder Público. O nítido paralelismo entre os quaestores, os praefecti aerarii e os atuais fiscais de tributos é tão saliente quanto a clara parecença entre os publicani, as societates publicanorum e os modernos estabelecimentos bancários. Ontem como agora, enquanto uns fiscalizavam, outros arrecadavam. Lá como aqui, uns agiam sob o aguilhão vigilante do direito público, enquanto os outros com a presença coadjuvante e auxiliar do direito privado. Em certo período da história de Roma, como entre nós, o regime especial da potestas (o poder de declarar a vontade do Estado), somente aos primeiros restava garantido. Todavia, para que não haja mal-entendido, convém, desde logo, ressaltar a existência de contrastes. Para não alongar a exposição, suficiente recordar que os publicanos (societates publicanorum) tinham a possibilidade, por força de uma lex censoria, de manejar medidas executivas - agindo em nome próprio, jamais como substituto processual do povo romano -, podendo-se valer, contra os devedores de impostos (vectigalia), da legis actio per pignoris capionem, conforme o testemunho, entre outros, de Gaius em suas Institutionum, Livro IV, § 28 (v. ZULUETA, Francis de. The Institutes of Gaius: Commentary. Oxford: Clarendon, 1967, v. 2, p. 248-249; Vide, ainda, MOREIRA ALVES, Direito..., p. 228, mais TUCCI, José Rogério Cruz e; AZEVEDO Luis Carlos. Lições de História do Processo Civil Romano. São Paulo: Revista dos Tribunais, 1996, p. 70). 
Convém realçar que até os defensores de regime jurídico uniforme e indistinto para servidores públicos e trabalhadores particulares não deixam de conceder a imperiosa necessidade, em certos casos, "de se examinar, cuidadosamente, quais seriam os postos da função pública que requerem especiais direitos e deveres e como deveriam esses direitos e deveres ser constituídos e matizados em vista de cada tarefa e cargo". ${ }^{50}$ Afinal, como pondera Martin Bullinger - um dos grandes defensores daquele mencionado regime uniforme -, "seria inoportuno que um oficial de portaria e um alto funcionário de Ministério fossem eventualmente submetidos a um regime jurídico substancialmente idêntico". ${ }^{11}$

Pois bem, com o advento da Emenda Constitucional $19 \mathrm{e}$, posteriormente, com a entrada em vigor da Lei 9.986/2000, o Poder Judiciário teve oportunidade de examinar a constitucionalidade de dispositivo que conferia aos servidores das Agências Reguladoras a condição de meros empregados públicos, justamente ao atuarem como reguladores. É que a EC 19 , ao tentar extinguir o "regime jurídico único", supostamente teria aberto espaço para que o art. $1^{\circ}$ da Lei 9.986, curvando-se às conveniências da hora, pudesse, sem considerações de fundo, determinar que "as Agências Reguladoras terão suas relações de trabalho regidas pela Consolidação das Leis do Trabalho, ..., em regime de emprego público".

Submetido, entretanto, à apreciação do Supremo Tribunal Federal (ADIn 2.310), esse dispositivo, tamanha a gritante incompatibilidade com a Lei Fundamental, felizmente teve sua eficácia, desde logo, suspensa. ${ }^{52}$

Com muita freqüência, o ponto de melhor visibilidade só se deixa alcançar pela arte da comparação e, por conseguinte, pelo respeito à regra de que aquilo que vale ou repugna a uma

50 BULLINGER, Martin. Öffentliches Recht und Privatrecht. Stuttgart: W. Kohlhammer, 1968, p. 101: "[...] müsste sorgfältig geprüft werden, für welche Positionen des öffentilichen Dienstes besondere Beamtenrechte und Beamtenpflichten überhaupt erforderlich und wie diese Rechte und Pflichten je nach der besonderen Aufgabe und Stellung verschieden zu gestalten sind".

51 Ibidem, p. 101: "So erweist es sich u.U. als nicht angebraucht, einen technischen Hausmeister und den höheren Beamten eines Ministeriums im wesentlichen demselben Beamtenrecht zu unterwerfen".

52 ADIn 2.310. Foi por esse motivo que a Constituição Alemã, de 23 de maio de 1949, no seu art. 33, alínea 4, preceituou que "l'exercice des droits de souveraineté doit être confié à titre permanent à des fonctionnaires publics ...", sendo que, neste mesmo artigo, a alínea 5 determina, ainda, que "le droit de la fonction publique doit être réglementé en tenant compte des principes traditionnels du fonctionnariat" (DUVERGER, Maurice (Org.) Constitutions et Documents Politiques. Paris: Presses Universitaires de France, 1981, p. 468). 
relação jurídica em particular, vale ou repugna a qualquer outra relação eventualmente assemelhada ou idêntica. Nessa ótica, o status dos servidores responsáveis pela Administração Tributária - munus relevante e desafiador - guarda semelhança, no âmago, com a situação jurídica descrita pela doutrina e chancelada pelo STF, na aludida ADIn 2.310. Com efeito, se no caso das Agências Reguladoras, em que havia regra legislada prescrevendo o contrário, já se afastou a possibilidade de utilização exclusiva do regime celetista, a fortirori se deve bani-lo, por inteiro, na seara da Administração Tributária, cujas funções exigiram, ao longo da história, um regime jurídico peculiaríssimo, atualmente reafirmado pelo inciso XXII acrescentado pela Emenda 42 ao art. 37 da Lei Fundamental. Em outras palavras, o caráter especial e estatutário das funções de "polícia administrativa", desempenhadas pela vinculada e indelegável fiscalização de tributos obteve sua máxima e palpável consagração com a regra que confirmou, quanto à Administração Tributária, a sua natureza de "atividade essencial ao funcionamento do Estado". É em tal contexto e com tal espírito que se deve interpretar, quer o inciso XXII do art. 37, quer o inciso IV do art. 167, ambos da CF.

Assim, dando continuidade, apesar de inúmeras variações políticas e ideológicas, a uma trajetória de resguardo dos núcleos estratégicos da Administração Pública, a EC 42, de modo não-excludente, imprimiu à atuação de determinados servidores o selo de "atividade essencial", coroando, com esse título, uma carreira de deveres austeros, de cujo serviço depende não só o financiamento do Estado, mas, em igual medida, o bem-estar da sociedade e a eficácia direta e imediata, no núcleo forte, dos direitos fundamentais de todas as dimensões.

Cumpre notar que o emprego da palavra "carreira" não constitui licença retórica, divorciada de fundamentos normativos ou constitucionais. Antes, a escolha dessa categoria deve ser creditada ao próprio constituinte que, em confluência com o atributo da essencialidade, consignou o alerta de que o quadro de pessoal da Administração Tributária da União, dos Estados e dos Municípios deve ser formado por "servidores de carreiras específicas". Aqui, a expressão "carreira" apresenta sentido técnico assaz preciso, querendo designar aqueles cargos de provimento efetivo - portanto estatutários - que, à diferença dos denominados "cargos isolados", se escalonam em classes hierarquizadas segundo o grau de responsabilidade ou de complexidade das atribuições funcionais..$^{53}$

Tal, porém, não é tudo. Há outra relevante perspectiva a ser investigada.

53 MEIRELLES, Hely Lopes. Direito Administrativo Brasileiro. São Paulo: Malheiros, 2001, p. 398, e BANDEIRA DE MELLO, Curso de..., p. 276. 
Decididamente, a alusão à carreira é mais rica do que se afigura à primeira vista. Ao que tudo indica, o uso do termo tem o fito de reforçar aquele almejado ambiente de "institucionalização da independência" (Institutionalisierung der Unabhängigkeit) $)^{54}$ com o escopo de erradicar, pelo menos em determinados domínios da Administração Pública, o regime de emprego celetista, ${ }^{55}$ no caso das funções essenciais que exigem o vínculo institucional.

Não foi por outro motivo que, na Alemanha, o Tribunal Constitucional (Bundesverfassungsgericht), referiuse ao "servidor público de carreira como uma instituição que, com fundamento em conhecimentos técnicos, desempenho profissional e leal cumprimento do dever, garante uma Administração estável, representando um fator de compensação em face das forças políticas conformadoras da vida do Estado". ${ }^{56}$ Mas o intento de consolidar o lastro de proteção jurídica imprescindível ao pleno e regular exercício da Administração marchou mais longe.

No caso da Administração Tributária, aqui tomado como caso emble- mático, por se tratar de segmento administrativo cuja performance repercute, em última instância, no custeio das atividades do Poder Público, o constituinte, numa inovação complementar, culminou por prescrever, em apoio àquela atmosfera de estabilidade, que "as administrações tributárias da União, dos Estados, do Distrito Federal e dos Municípios, ... terão recursos prioritários para a realização de suas atividades". Para tanto, o constituinte derivado tornou-a exeqüível - essa reserva de "recursos prioritários" -, com o alargamento das exceções constantes do inciso IV do art. $167 \mathrm{da}$ CF. Como se vê, desde a promulgação da EC 42, viabilizou-se "a vinculação de receita de impostos ... para realização de atividades da administração tributária".

O que se observa, portanto, é que todas essas modificações, somadas às conquistas sedimentadas pela doutrina e pela jurisprudência, exprimem, da parte do Congresso Nacional, uma inegável - quiçá surpreendente solicitude no sentido de alargar a rede de proteção em torno do "poder de polícia" tributária.

54 ZIPPELIUS, Reinhold. Allgemeine Staatslehre. München: C.H. Beck'sche, 1999, p. 382 .

55 A despeito de também os empregados públicos serem concursados e de terem algumas garantias que decorrem de princípios de direito público que incidem em tais relações. Sobre o tema, vide FREITAS, Ney. Dispensa de Empregado Público e o Princípio da Motivação. Curitiba: Juruá, 2002.

56 In $B v \operatorname{erf} G E, 7,162$ : “... Berufsbeamtentum als eine Institution ..., die gegründet auf Sachwissen, fachliche Leistung und loyale Pflichterfüllung, eine stabile Verwaltung sichern und damit einen ausgleichenden Faktor gegenüber den das Staatsleben gestaltenden politischen Kräften darstellen soll." 
Cuida-se de bom exemplo do zelo com setores estratégicos da Administração na luta brava contra a intrépida inventividade das fraudes e sonegações. Daí a unidade finalística das mudanças, cujo alvo está em fundar, com firmes declarações de estatura constitucional, a independência dos fiscais de tributo, incluindo-os, desde já, no rol das carreiras de Estado, e, de outro lado, irrigando-os com dotações orçamentárias capazes de arcar, pela via da vinculação de receitas fiscais, com os custos do aparato fiscalizatório e de suas inerentes garantias.

Em síntese, é da essência do "poder de polícia", em qualquer das instâncias da Federação, estruturar-se a partir de carreira de servidores públicos estatutários, formada por cargos de provimento efetivo, devidamente concursados e dotados das garantias aptas a minimizar os efeitos deletérios da política episódica. Se é verdade que a função fiscalizatória ajuda a consolidar, no exemplo dado, a arrecadação de tributos e, por conseguinte, a eficiência do sistema tributário, não menos verdade que à fraqueza dos instrumentos de controle também se pode imputar o progressivo exaurimento das reservas públicas.

Privados, simultaneamente, de servidores estatutários e de rubricas de custeio autônomas, os órgãos de controle fiscal poderiam acabar vítimas da inanição orçamentária ou dos famigerados contingenciamentos (que ameaçam, assinale-se de passagem, mortalmente, a independência das agências reguladoras) e das conveniências externas, cumulativamente espoliados pelos interesses partidários ou pela insopitável astúcia.

Como se percebe, afortunadamente, o ordenamento brasileiro, no concernente à Administração Tributária, premuniu-se contra tais riscos por meio de quatro disposições com eficácia imediata e vinculante em todas as esferas da Federação. Primeira: as competências da Administração Tributária só podem ser exercidas por pessoas jurídicas de direito público. Verdade que o caput do art. $7^{\circ}$ do CTN já não deixava margem para maior controvérsia: quando se trata de fiscalização tributária, somente instituições de direito público podem desempenhá-las. Segunda: à luz da Constituição emendada (inciso XXII, art. 37), apenas o servidor público estatutário (estável, nos termos do art. 41 da CF) e de carreira reúne as credenciais necessárias e suficientes para se desincumbir das tarefas da Administração Tributária. O que a EC 42 teve em vista, com a ressalva de que o trabalho de fiscalização deve ser conduzido por servidores públicos, foi criar situação independente e garantida, capaz de propiciar o desenvolvimento de uma carreira de Estado (não meramente "governativa"), com os atributos do profissionalismo e da estabilidade, sem os quais se corre o risco de transformar a máquina pública em presa das apreensões com a subsistência. Terceira: o inciso XXII acrescentado ao art. 37 da CF não visou 
a, tão-somente, impor o regime estatutário de carreira. O seu intuito foi também de conceder às carreiras da Administração Tributária o status de "atividades essenciais ao funcionamento do Estado". Isso significa que o constituinte, antecipando-se lucidamente a Projetos que versam sobre as carreiras de Estado, atribuiu aos fiscais de tributos da União, dos Estados e dos Municípios, de forma cogente e autoaplicável, o título de "Carreira de Estado", com todos os consectários jurídico-constitucionais. Quarta: o inciso IV do art. 167, combinado com a parte final do citado inciso XXII do art. 37, ambos da CF, asseguram às administrações tributárias da União, dos Estados e dos Municípios, pela via da "vinculação de receita de impostos", a destinação orçamentária de "recursos prioritários para a realização de suas atividades". É como se a administração de tributos passasse a desfrutar de fonte orçamentária específica, destinada a cobrir o custeio, inclusive salarial e previdenciário, da estrutura afeita à fiscalização e cobrança. Como o poder de tributar nada seria sem o eficiente poder de fiscalizar, o constituinte houve por bem garantir à federação, em todos as instâncias, uma administração independente, não só do ponto de vista funcional, mas, também, no campo econômico-financeiro. Autonomia real, espera-se. Com efeito, se a administração de tributos não gozasse de independência quanto às dotações orçamentárias, aquela outra independência, a de natureza funcional, restaria prejudicada, em todos os sentidos, dado que o livre manejo das verbas de custeio poderia comprometer qualquer autonomia estatutária fundada em abstratas prescrições. Logo, buscando inspiração novamente em Alexander Hamilton, é o caso de assinalar: o poder sobre a subsistência da Administração implica o poder sobre a eficácia da Administração Pública.

Mais: os administradores tributários mantêm vinculação institucional, que supõe tratamento prudente e diferenciado (sem configuração de qualquer privilégio), preservadas as garantias que fazem as vezes de escudos contra a falta de continuidade das políticas públicas e a precariedade de regime que, não raro, propicia o tormentoso arbítrio. Em outras palavras, o administrador, que entretém vínculo institucional (não-contratual), é aquele concursado que pode aspirar, diferentemente do empregado, uma estabilidade no serviço público (e não no cargo), um dos elementos constitutivos do regime estatutário. O tema merece breve tratamento em tópico específico.

\section{ESTABILIDADE E CARREIRAS DE ESTADO}

A estabilidade na carreira de Estado, para além das mudanças pontuais no tocante a regras, deveria ser vista como qualificada, desempenhando valiosa tríplice função. De fato, tal proteção de alçada constitucional colima garantir a manutenção das políticas públicas, uma vez que são 
os servidores estáveis que asseguram a permanência das metas do Estado (de longo prazo), sem prejuízo das alterações conjunturais, a cargo dos agentes políticos, transitórios por definição. A estabilidade oferece, ainda, ao servidor que responde por atividade essencial de Estado a salvaguarda contra a prepotência dos mandantes de turno, não raro travestida de "discricionariedade". Como acentuado, sem a independência e a segurança oferecidas pela garantia da estabilidade, o cidadão logra ter menores chances de prestação adequada dos serviços essenciais. A terceira função da estabilidade reside na contrapartida que o regime institucional (nãocontratual) oferece à vista da periclitante lâmina posta à disposição do Poder Público sob a forma de poderio unilateral (ainda que mitigado) de alteração das regras do regime.

No intuito de cumprir a tríplice função, a estabilidade no serviço público deve ser compreendida como proteção de alçada constitucional contra a perda do cargo, conferida a titular de cargo efetivo, nomeado em razão de concurso público, após o desenrolar do período de estágio probatório (presentemente, a regra é de três anos de real exercício no cargo) e mediante avaliação exitosa ao cabo do aludido estágio. Indispensável a conjugação do prazo e da aprovação por intermédio de comissão de estáveis, designada para tal fim (CF, art. 41, § 4o).

A calhar, de passagem, convém passar ao exame das situações de perda do cargo do servidor estável oriundas da Emenda Constitucional 19/ 98. À primeira vista, exsurgem quatro hipóteses para a referida perda do cargo. Contudo, uma delas resulta apenas aparente, de maneira que, a bem do rigor, são mais propriamente três as situações em que se admite a desvinculação compulsória do agente dotado dessa garantia. Uma a uma, cumpre fazer menção às circunstâncias de perda do cargo público. A primeira hipótese, nitidamente de cunho punitivo, segue da sentença transitada em julgado (art. 41, § 1o, I): invalidada por sentença a demissão do servidor estável aplica-se, nesse caso, a regra prevista no $\S 2^{\circ}$, cumprindo reintegrar o servidor no cargo. A segunda hipótese (não necessariamente de penalidade demissória) concerne ao processo administrativo, assegurada a ampla defesa (art. $41, \S$ 10 , II). A terceira hipótese é a relacionada à insuficiência de desempenho, matéria pendente de regulamentação por intermédio de lei complementar (CF, art. $41, \S 1$ o, III), que não deve resvalar para o alargamento das sombrias veredas do arbítrio (discrição nãomotivável) ou da violação do devido processo (material e formalmente considerado).

Tais hipóteses decorrem, no geral das vezes, de penalidades demissórias, porém a segunda hipótese pode abarcar situação de mera desinvestidura, desde que conjugada ou entrelaçada à dicção do art. $169, \S 4^{\circ}, \mathrm{CF}$. Na leitura 
sistemática, ${ }^{57}$ revela-se aconselhável * compreender que o constituinte quis apenas punir severamente o servidor público que, de modo culposo grave ou doloso, tornar insustentável a mantença do vínculo institucional. Nada obstante, $o$ aludido liame perece somente se o laço com o Poder Público restar, de modo irremissível, maculado pela conduta inaceitável do agente público, no caso das carreiras de Estado. Note-se que a suposta quarta hipótese autônoma do deslocado art. $169, \S 4^{\circ},{ }^{58} \mathrm{em}$ realidade encontra-se absorvida na segunda possibilidade elencada, pois também aí se exige processo administrativo cercado de todas as garantias. A "quarta" hipótese, trazida pelo art. 169, traduz desligamento sem conteúdo punitivo (dado que inexiste caráter sancionatório), oriundo do enxugamento de despesas, e requer o processo administrativo estatuído no art. $41, \S 10$, II, sem embargo de relevantes acréscimos de cautelas, mostrando-se, na prática, inviável para os ocupantes de cargos essenciais ao funcionamento do Estado.

Apresenta-se a hipótese do art. 169, $\S 4^{\circ}, \mathrm{CF}$, como recurso derradeiro para fazer observar os limites de despesas com pessoal, estatuídos em lei complementar (Lei Complementar 101/ 2000). Assim, se medidas prévias não renderem resultado suficiente, o servidor estável poderá, em última instância, perder o cargo, "desde que ato normativo motivado de cada um dos poderes especifique a atividade funcional, o órgão ou unidade administrativa objeto da redução de pessoal", vedada a discricionariedade pura. ${ }^{59}$ Todavia, uma motivação congruente, clara e aceitável será virtualmente impossível para o enxugamento de servidores que desempenharem atividades essenciais ao funcionamento estatal, sob pena de destruição do próprio Estado! O constituinte não pode ter pretendido pedir que, em nome da austeridade fiscal, o Estado se destrua.

Vai daí a implicação decisiva do argumento: mostra-se factível, por meio de interpretação sistemática, acentuar a concordância prática dos preceitos em tela, de modo a salvaguardar a proporcionalidade e a afastar a aplicação do art. 169 da CF em relação

57 Para uma visão mais aprofundada do tema, vide FREITAS, Juarez. A Interpretação Sistemática do Direito. 4. ed. São Paulo: Malheiros, 2004.

$58 \mathrm{Art} .169, \S 4^{\circ}, \mathrm{CF}$ "Se as medidas adotadas com base no parágrafo anterior não forem suficientes para assegurar o cumprimento da determinação da lei complementar referida neste artigo, o servidor estável poderá perder o cargo, desde que ato normativo motivado de cada um dos Poderes especifique a atividade funcional, o órgão ou unidade administrativa objeto da redução de pessoal."

59 Toda discricionariedade está vinculada aos princípios fundamentais. A propósito, vide FREITAS, J., $O$ Controle dos Atos..., 
aos ocupantes de cargos essenciais ao funcionamento do Estado. Eis o caminho mais equilibrado, que produz a tranqüilização do servidor de carreira exclusiva de Estado. Reiterando: a obediência aos limites da Lei de Responsabilidade Fiscal, nos termos preconizados pelo art. $169 \mathrm{da}$ CF, não pode conduzir o Estado ao suicídio.

Inquestionável que se encontra subjacente ao asseverado o forte apreço devotado aos que deliberaram investir suas energias numa carreira pública árdua, a qual, bem entendida, demanda pronunciada abnegação, mormente em face das múltiplas restrições imanentes ao regime publicista. Ao fim e ao cabo, a estabilidade nada mais representa do que contrapartida para as sérias restrições e desvantagens trazidas por relação não-contratual. Por idêntico motivo, é pertinente afirmar que, no caso emblemático dos fiscais tributários, não faz sentido admitir ocupante de cargo de confiança para o desempenho das funções inerentemente de Estado. Os cargos em comissão podem ser direcionados para funções de apoio, tão-somente. Por isso, os cargos de direção, na Administração Tributária, devem ser reservados apenas aos servidores de carreira.

Tudo considerado, os administradores que exercerem funções típicas e finalísticas de Estado (funções essenciais), além de terem a garantia de acesso impessoal do concurso público, merecem a proteção adicional de robustos anteparos formais e substanciais contra voluntarismos persecutórios ou enxugamentos fiscais lineares e destituídos de motivação razoável. Tais anteparos não devem servir, está claro, para acomodação dos agentes públicos, mas para que possuam uma couraça protetiva. Essa segurança mínima, em vez de estimular a indolência, é benfazeja para o cumprimento fiel dos princípios constitucionais, em lugar da obediência acrítica aos ditames ou influências dos chefes ou poderosos da hora. Vez por todas, a garantia patrocinada pela estabilidade do art. 41 da CF deve ser concebida como proteção oferecida à sociedade, donde segue não haver motivo para antagonizar os qualificadamente estáveis. Em lugar da hostilidade, a estabilidade peculiar da carreira de Estado deve ser entendida como requisito para impedir que se torne postiço o Estado democrático, sem prejuízo da luta contínua para que os agentes estatais pautem as suas condutas sob o manto sagrado dos princípios e da eficácia direta e imediata dos direitos fundamentais.

\section{CONCLUSÕES}

Tendo em conta o articulado, eis as principais proposições conclusivas:

a) Há carreiras essenciais ao funcionamento do Estado (por exemplo, auditores fiscais), o que determina regime peculiar de natureza institucional, com a estabilidade qualificada do art. $41 \mathrm{da} C F$, sem aplicação plausível, nesse caso, da hipótese trazida pelo art. $169, \S 4^{\circ}, \mathrm{CF}$. 
b) Somente pessoa jurídica de direito público pode exercer competências privativas da Administração, uma vez que se inserem no âmbito indelegável da "utilização de poderes de soberania" (Ausübung hoheitsrechlicher Befugnisse). ${ }^{60}$

c) Apenas servidor de carreira e, por conseguinte, ocupante de cargos de provimento efetivo, pode executar as funções peculiares à fiscalização, haja vista que as suas tarefas são de cunho permanente (ständige Aufgabe ${ }^{61} \mathrm{e}$, ao pressuporem "utilização de poderes de soberania" (Ausübung hoheitsrechlicher Befugnisse), exigem, por simetria, o arrimo estatutário de um "status especial" (besonderen status). ${ }^{62}$

d) Cumpre registrar que a alusão à carreira constante do inciso II, do art. 37 da CF designa, antes de mais nada, aqueles cargos estatutários de provimento efetivo que, em contraste com os cargos isolados, são escalonados em classes hierarquizadas de acordo com o grau de responsabilidade e de complexidade das funções. Mas não é só. Tal referência também exprime a preocupação do constituinte de criar ambiente institucional propício ao desenvolvimento de carreira cercada das garantias de direito público, capazes de situar determinados agentes públicos a salvo dos incidentes da política governamental transitória.

e) $\mathrm{O}$ legislador infraconstitucional, ao definir as carreiras de Estado, deveria, por exemplo, deixar estampada a interpretação aqui defendida quanto às hipóteses de perda do cargo elencadas no art. 169 , com a redação dada pela EC 19. Deve, ademais, deixar claro que os cargos de direção e de chefia, diretamente envolvidos com "atividade-fim", precisam ser ocupados por membros de carreira, dada a natureza das tarefas e das garantias correspondentes.

\section{REFERÊNCIAS}

ACHTERBERG, Norbert. Allgemeines Verwaltungsrecht. Heidelberg: Decker, C. F. Müller, 1982.
ARANGIO-RUIZ, Vincenzo. Storia del Diritto Romano. Napoli: Eugenio Jovene, 1968.

60 HESSE, Grundzüge..., p. 218 . Vide, também, as alíneas 4 e 5 do art. 33 da Constituição Alemã, as quais determinam que o exercício de poderes ou de direitos de soberania deve ser confiado exclusivamente a funcionário público regido pelos princípios tradicionais do funcionalismo.

61 Ibidem, p. 218.

62 Ibidem, p. 218 . Nesta mesma linha, vide WOLFF, Hans J.; BACHOF, Otto. Verwaltungsrecht. München: C.H. Beck'sche, 1976, v. 2, p. 486: “[... ] einen besonderen rechtlichen Status". 
BALEEIRO, Aliomar. Direito Tributário Brasileiro. Rio de Janeiro: Forense, 2004.

BANDEIRA DE MELLO, Celso Antônio. Curso de Direito Administrativo. São Paulo: Malheiros, 2003.

BONAVIDES, Paulo. Curso de Direito Constitucional. São Paulo: Malheiros, 1996.

BULLINGER, Martin. Öffentliches Recht und Privatrecht. Stuttgart: W. Kohlhammer, 1968.

CASSESE, Sabino. Tendenze e Problemi del Diritto Amministrativo. Rivista Trimestrale di Diritto Pubblico, 54, p. 901-912, 2004.

DI PIETRO, Maria Sylvia Zanella Direito Administrativo. São Paulo: Atlas, 2001.

DUGUIT, Leon. Traité de Droit Constitutionnel. Paris: Ancienne Librairie Fontemoing, 1930. v. 3.

DUVERGER, Maurice (Org.) Constitutions et Documents Politiques. Paris: Presses Universitaires de France, 1981.

FLEINER, Fritz. Droit Administratif Allemand. Tradução Dh. Eisenmann. Paris: Librairie Dalegrave, 1933.

FREITAS, Juarez. O Controle dos Atos Administrativos e os Principios Fundamentais. 3. ed. São Paulo: Malheiros, 2004.

\section{Estudos de Direito} Administrativo. São Paulo: Malheiros, 1995.
. A Interpretação Sistemática do Direito. 4. ed. São Paulo: Malheiros, 2004.

FREITAS, Ney. Dispensa de Empregado Público e o Princípio da Motivação. Curitiba: Juruá, 2002.

GANGEMI, Lello. Elementi $d i$ Amministrazione Finanziaria Pubblica. Padova: CEDAM, 1934.

HAMILTON, Alexander. The Federalist. Chicago: Encyclopaedia Britannica, 1952. v. 43.

HARIOU, Maurice. Pages de Doctrine. Paris: LGDJ, 1980. v. 1.

HARIOU, Maurice. Précis Élémentaire de Droit Administratif. Paris: Recueil Sirey, 1938.

HENSEL, Albert. Diritto Tributario. Tradução Dino Jarach, Milano: Giuffrè, 1956.

HESSE, Konrad. Grundzüge des Verfassugsrechts der Bundesrepublik Deutschland. Heidelberg: C. F. Müller Juristischer, 1978.

JÈZE, Gaston. Les Principes Généraux du Droit Administratif. Paris: Marcel Giard, 1930.

KASER Max. Das Römische Privatrecht. München: C.H. Beck'sche Verlagsbuchhandlung, 1955.

KUNKEL, Wolfgang. Römische Rechtsgeschichte. Köln: Böhlau, 1956.

LE DROIT Public de L'Empire Allemand. Tradução C. Gandilhon e TH. Lacuire. Paris: V. Giard, E. Brière, 1901. v. 2. 
LIMA, Ruy Cirne. Principios de Direito Administrativo. São Paulo: Revista dos Tribunais, 1982.

MACHADO, Hugo de Brito. Comentários ao Código Tributário Nacional. São Paulo: Atlas, 2003. v. 1.

MACHADO, Hugo de Brito. Curso de Direito Tributário. São Paulo: Malheiros, 2004. . Estudos de Direito Penal Tributário. São Paulo: Atlas, 2002.

MAURER, Hartmut. Allgemeines Verwaltungsrecht. München: C.H. Beck'sche, 1985.

MAYER, Otto. Droit Aministratif Allemand. Paris: V. Giard; E. Brière, 1906. v. 4.

MEDAUAR, Odete. Direito Administrativo Moderno. São Paulo: Revista dos Tribunais, 2002.

MEIRELLES, Hely Lopes. Direito Administrativo Brasileiro. São Paulo: Malheiros, 2001.

MIRANDA Pontes de. Comentários à Constituição de 1967 com a Emenda $n^{\circ} 1$ de 1969. São Paulo: Revista dos Tribunais, 1973.v. 3.

MOMMSEN, Théodor. Manuel des Antiquités Romaines. Tradução Paul Frédéric Girard. Paris: Thorin et Fils, 1894. v. 4.

MORAES, Bernardo Ribeiro de. Compêndio de Direito Tributário. Rio de Janeiro: Forense, 1993.v. 1. MOREIRA ALVES, José Carlos. Direito Romano. Rio de Janeiro: Forense, 1971.v. 1.
MOREIRA NETO, Diogo de Figueiredo. Curso de Direito Administrativo. Rio de Janeiro: Forense, 2003.

ORESTANO, Ricardo. Il Problema delle Persone Giuridiche in Diritto Romano. Torino: G. Giappichelli, 1968.

PORTUGAL. Ordenações Afonsinas. Lisboa: Calouste, 1984. v. 1. Livro 1.

TACITO. The Annals. Tradução Alfred John Church e William Jackson Brofribb. Chicago: Great Books, [s.d.]. v. 15.

TUCCI, José Rogério Cruz e; AZEVEDO Luis Carlos. Lições de História do Processo Civil Romano. São Paulo: Revista dos Tribunais, 1996.

WAGNER, Adolf. Traité de la Science des Finances. Tradução Jules Ronjat. Paris: V. Giard, E. Brière, 1909.

WHITE, Leonard. Introduction to the Study of Public Administration. New York: The Macmillan, 1957.

WOLFF, Hans J.; BACHOF, Otto. Verwaltungsrecht. München: C.H. Beck'sche, 1976. v. 2.

ZIPPELIUS, Reinhold. Allgemeine Staatslehre. München: C.H. Beck'sche, 1999.

ZULUETA, Francis de. The Institutes of Gaius: Commentary. Oxford: Clarendon, 1967. v. 2. 